\title{
Metronidazole-induced cerebellar toxicity
}

\author{
Jonathan A. Chatzkel • Arastoo Vossough
}

Received: 4 September 2009 / Accepted: 23 September 2009 /Published online: 14 November 2009

(C) Springer-Verlag 2009

A 15-year-old girl presented with ataxia and dysmetria 7 days after beginning treatment with metronidazole for Crohn disease. MRI revealed bilateral symmetric T2/ FLAIR hyperintense lesions of the dentate nuclei (Fig. 1). The lesions did not show contrast enhancement or restricted diffusion. No other lesions were seen. The lesions resolved completely after metronidazole was discontinued (Fig. 2).

Metronidazole is an antibiotic used in the treatment of Crohn disease and anaerobic-related infections [1]. Metronidazole-induced cerebellar toxicity is a rare complication. Patients often present with cerebellar symptoms, including

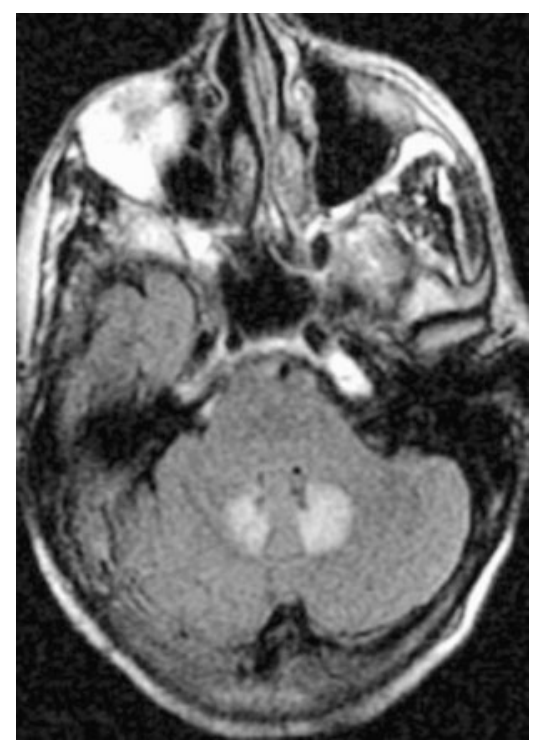

Fig. 1 Axial FLAIR image

\footnotetext{
J. A. Chatzkel · A. Vossough $(\bowtie)$

Department of Radiology, Children's Hospital of Philadelphia, University of Pennsylvania School of Medicine,

34th St. and Civic Center Boulevard,

Philadelphia, PA 19104, USA

e-mail: vossough@email.chop.edu
}

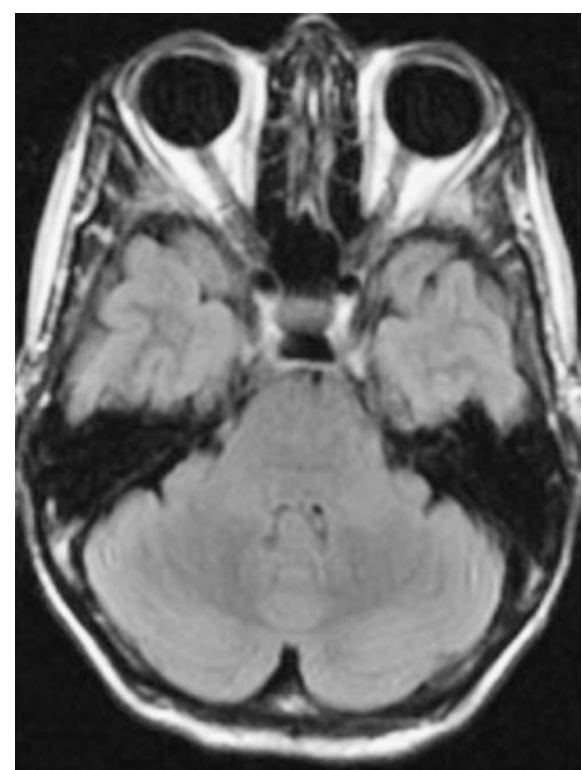

Fig. 2 Axial FLAIR image shows complete resolution

ataxia or dysarthria, which often gradually resolve after ceasing treatment [2]. The most characteristic radiological finding is bilateral symmetric hyperintense lesions of the dentate nuclei [1], and less commonly the brainstem, corpus callosum, and subcortical white matter.

Neurotoxicity should be suspected in patients presenting with cerebellar symptoms in the presence of treatment with metronidazole.

\section{References}

1. Kim E, Na DG, Kim EY et al (2007) MR imaging of metronidazole-induced encephalopathy: lesion distribution and diffusion-weighted imaging findings. AJNR 28:1652-1658

2. Patel K, Green-Hopkins I, Lu S et al (2008) Cerebellar ataxia following prolonged use of metronidazole: case report and literature review. Int J Infect Dis 12:e111-114 